\title{
GEOAMBIENTES DO PARQUE ESTADUAL DO IBITIPOCA, MUNICÍPIO DE LIMA DUARTE-MG ${ }^{1}$
}

\author{
Herly Carlos Teixeira Dias², Elpídio Inácio Fernandes Filho ${ }^{3}$, Carlos Ernesto Gonçalves Reynaud Schaefer³, \\ Luiz Eduardo Ferreira Fontes ${ }^{3}$ e Leonardo Barros Ventorim ${ }^{4}$
}

\begin{abstract}
RESUMO - Foram identificados, mapeados e caracterizados os geoambientes do Parque Estadual do Ibitipoca (PEI), Minas Gerais, com o objetivo de subsidiar o manejo ecológico da área. Para este fim, realizaram-se coletas de solos, em pontos georreferenciados por GPS (Global Positioning System), fotointerpretações a partir de ortofotos e uso de mapas planialtimétricos, além de intenso reconhecimento de solos no campo. Oito geoambientes foram identificados e caracterizados: (1) Patamares com Espodossolos, 2) Cristas Ravinadas, 3) Escarpas, 4) Grotas, 5) Mata Baixa com Candeia, 6) Mata Alta sobre Xisto, 7) Topos Aplainados e 8) Rampas com Vegetação Aberta. Em cada ambiente a vegetação associada é fortemente condicionada pela profundidade do solo e pelo tempo de permanência de água no sistema. Os ambientes de mata, tanto sobre xistos quanto sobre quartzitos, sofrem menor estresse hídrico, seja por melhores condições físicas do solo e maior retenção de água, seja pela presença de ambiente mais ombrófilo e úmido, como nas Grotas. Os geoambientes florestados possuem concentrações de P e $\mathrm{K}$ mais elevadas do que nos ambientes campestres abertos. No geoambiente de Mata Baixa com Candeia, a pobreza química do substrato parece ser o impedimento à ocorrência de uma floresta mais densa. Os Campos de Altitude ocorrem nas altitudes mais elevadas no PEI, sendo desenvolvidos sobre solos mais profundos do que sob campos rupestres, onde há freqüente exposição da rocha ou solos muito rasos.
\end{abstract}

Palavras-chave: Ecologia da paisagem, geoambientes, Parque Estadual do Ibitipoca, mata nativa e relação solo vegetação.

\section{GEOENVIRONMENTS OF THE IBITIPOCA STATE PARK, LIMA DUARTE, MINAS GERAIS}

\begin{abstract}
The geoenvironments of the Ibitipoca State Park, Minas Gerais were characterized and mapped to provide sound, sustainable ecological management of the area. Soil samples were collected and analyzed, with emphasis on chemical and physical attributes. Photo-analyses were carried out on ortophotographs and planialtimetric maps, compled with extensive soil survey in the field. Eight geo-environments were identified: (1) The podzol slopes and plains, (2) the ridges with ravines, (3) escarpments, (4) concave gullies, (5) lowstand "Candeia" forest, (6) tall forest on schist, (7) upslope flat tops and (8) pediments with open vegetation. In each geoenvironment, the vegetation is closely associated with soil depth and soil moisture regime. The geoenvironments under forest, both on schists and quartzites, are subjected to lower water deficit compared with the others. This is either due to physical properties such as higher moisture or less evapotranspiration or with ombrophilous environments. This latter characteristic is typical of the concave deep gullies. In forest geoenvironments, $P$ and $K$ concentrations were generally higher than in the open grass geoenvironments. The low-stand "Candeia" forest is closely related to its very low nutrient status and less dense forest cover. "Campo de Altitude" (high altitude grasslands) is favoured by both high topographical position and exposure to cold winds, contrasting with the "campo rupestre" (rupiculous field grasslands). The former occurs in deeper soils, whereas the latter is associated with shallow soils and rock outcrops.
\end{abstract}

Key words: Landscape ecology, geoenvironments, Ibitipoca State Park, Atlantic rainforest, soil-vegetation relationship.

1 Recebido para publicação em 16.11.2000.

Aceito para publicação em 3.12.2002.

2 Prof. D.S., Departamento de Engenharia Florestal da Universidade Federal de Viçosa - UFV, 36571-000 Viçosa-MG, <herly@solos.ufv.br>; ${ }^{3}$ Prof. D.S., Departamento de Solos da UFV; ${ }^{4}$ Bolsista Iniciação Científica, CNPq, Departamento de Solos da UFV. 


\section{INTRODUÇÃO}

O Parque Estadual do Ibitipoca (PEI) está situado no distrito de Conceição do Ibitipoca, no município de Lima Duarte, sudeste de Minas Gerais, entre as coordenadas geográficas $21^{\circ} 40^{\prime}-21^{\circ} 44^{\prime} \mathrm{S}$ e $43^{\circ} 52^{\prime}-43^{\circ} 55^{\prime} \mathrm{W}$, abrangendo 1.488 ha da Serra do Ibitipoca, em altitudes que variam de 1.050 a $1.784 \mathrm{~m}$ (Feio, 1990; Fontes, 1997).

Para proceder a qualquer intervenção no referido parque, Wilcox (1978) recomendou a criação de um plano de manejo, com as necessárias caracterizações geológica, pedológica, hídrica e biótica local. Costa et al. (1998) classificaram o PEI na categoria de "Extrema Importância Biológica", em razão do endemismo de anfíbios, mamíferos e aves ameaçados e da relevância, da singularidade espeleológica e da diversidade de habitats. Os autores consideram que a maior pressão antrópica sobre a área é efetuada pelo turismo e recomendam o monitoramento da fauna, a ampliação dos limites do parque e o estudo dos impactos do turismo. Para o planejamento das Unidades de Conservação do Estado de Minas Gerais, de modo geral, Costa et al. (1998) relacionam, entre os problemas detectados, falhas na disponibilidade de informação sobre as características físicas, biológicas e de infra-estrutura e falta de planos de manejo/gestão, recomendando criar e implementar um banco de dados sobre áreas protegidas no Estado de Minas Geais, elaborar e implementar zoneamento e planos de manejo/ gestão, entre outros. Muitos trabalhos têm sido realizados, ainda que voltados principalmente ao meio biótico (SEMINÁRIO DE PESQUISA SOBRE O PARQUE ESTADUAL DO IBITIPOCA, 1997), com algumas análises e considerações gerais sobre os solos de ocorrência no PEI (Rocha, 1997).

No contexto deste trabalho, o termo "geoambiente" pode ser definido como ambiente geográfico que em uma extensão territorial apresenta homogeneidade com relação a determinados fatores ambientais de interesse ou a maioria deles. Assim, um conhecimento maior dos vários estratos ou geoambientes torna-se indispensável para nortear o planejamento e a gestão das unidades de conservação (UC).

Com base no exposto, os objetivos deste trabalho foram a identificação, a caracterização e o mapeamento dos geoambientes do Parque Estadual do Ibitipoca, utilizando uma metodologia pedogeomorfológica, de forma a subsidiar as estratégias de manejo e visitação do parque.

\section{MATERIAL E MÉTODOS}

\section{1. Área de Estudo}

A Figura 1 ilustra a localização do parque no Estado de Minas Gerais, bem como outras áreas de ocorrência de campo de altitude sobre o quartzito.

De acordo com Feio (1990), o clima característico é o tropical de altitude, com verões amenos (Cwb de Köppen). O regime de precipitação apresenta ciclo bem definido, com verão chuvoso e inverno seco, sendo junho, julho e agosto os meses mais secos e novembro, dezembro e janeiro os mais chuvosos, com precipitações médias anuais de $1.395 \mathrm{~mm}$.

Os registros da estação meteorológica localizada no parque mostram que a temperatura média mínima no verão é de $21,5^{\circ} \mathrm{C}$ e a máxima, de $36^{\circ} \mathrm{C}$; no inverno, estas temperaturas são de 2 a $14,5^{\circ} \mathrm{C}$.

Em 1999, o PEI recebeu 45.382 visitantes, dos quais 8.880 ficaram acampados. Os meses com maior número de visitantes foram janeiro e fevereiro (11.840), abril (5.927), julho (5.133) e setembro e outubro (8.142).

\subsection{Estratificação das Unidades Geoambientais}

Para estratificação das unidades geoambientais, utilizou-se uma metodologia pedogeomorfológica, estratificando as unidades e identificando as características ecogeográficas (rocha-mãe, solos, relevo, vegetação) e os problemas geoambientais associados (Tricart \& Kiewitdejonge, 1992; Schaefer, 1997). Para este fim, foram utilizados ortofotocartas (COMPANHIA... CEMIG, 1987), um mapa planialtimétrico do Iga (1986), todos na escala 1:10.000, além de toda a base de dados já produzidos no PEI e em visitas de campo, percorrendo intensamente a área de estudo. A partir do reconhecimento de campo e da identificação nos mapas-base, os geoambientes foram demarcados em papel-acetato, na rede de drenagem e nas vias de acesso. Na digitalização e edição dos mapas foram utilizados os programas ARC/INFO (Esri, 1994) e Arcview Gis (Esri, 1998).

Foram abertos 12 perfis de solos representativos da área (Figura 2), de acordo com as feições pedogeomorfológicas. Para melhor caracterização e classificação dos solos, procedeu-se à coleta de amostras, que foram encaminhadas para análises químicas e físicas. $\mathrm{O}$ local onde foram coletados os perfis de solos foi 
georreferenciado com uso de GPS (Global Positioning System) de navegação. As análises foram feitas em laboratórios do Departamento de Solos da Universidade Federal de Viçosa. Com exceção da análise de carbono total, todas as demais seguiram os métodos da EMPRESA...- EMBRAPA (1997).

\section{RESULTADOS E DISCUSSÃO}

A metodologia utilizada para identificação de geoambientes permitiu separar oito unidades ambientais dentro do PEI, conforme pode ser observado no mapa de geoambientes (Figura 3). Estas unidades foram caracterizadas conforme atributos geológicos, geomorfopedológicos e vegetacionais (Quadro 1). A seguir encontram-se as descrições das unidades geoambientais representadas no mapa.

\subsection{Patamares com Espodossolos}

São áreas aplainadas em patamares, em vários níveis, localizados na porção norte, correspondendo a 4\% da área total do parque. Ocorrem em relevos suaveondulados com concentração de areias quartzosas,

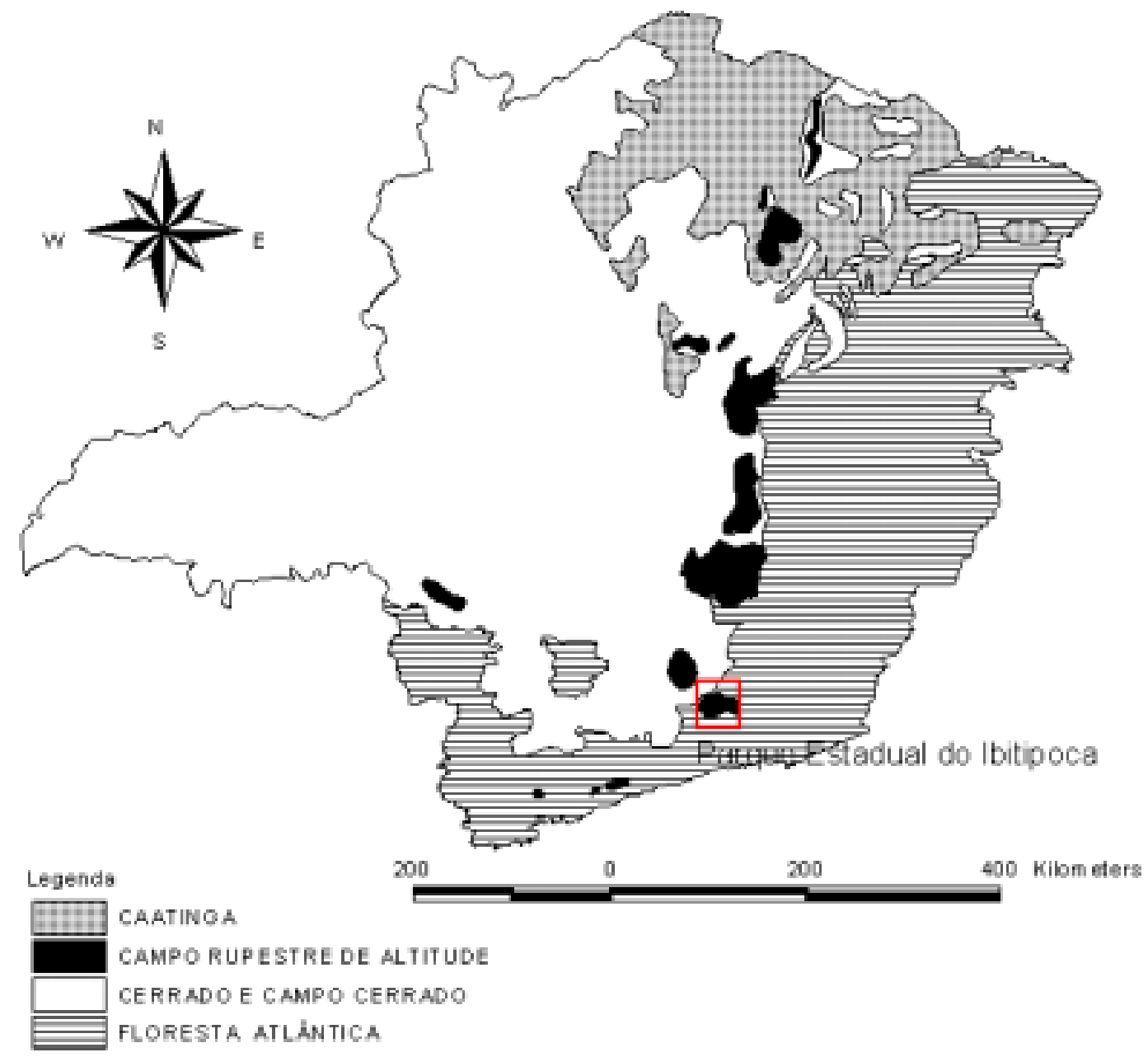

Figura 1 - Localização do Parque Estadual do Ibitipoca e de outras áreas com ocorrência de Campo de Altitude no Estado de Minas Gerais, Brasil (adaptado de EMATER/Geominas).

Figure 1 - Location of the Ibitipoca State Park and distribution of "Campo de Altitude" vegetation in Minas Gerais, Brazil (adapted from EMATER/Geominas). 
espraiadas em leques aluviais ou paleocanais, provenientes da decomposição e do transporte de produtos da decomposição do quartzito. São normalmente associados a Espodossolos. A vegetação de campo de altitude de caráter aberto encontrado nesse padrão é típica dos ambientes distróficos areno-quartzosos e muito lixiviados do PEI.

A rocha predominante na unidade é o quartzito, que é encontrada também nas unidades Cristas Ravinadas, Escarpas, Grotas, Mata Baixa com Candeia, Topos Aplainados e Rampas com Vegetação Aberta. Portanto,

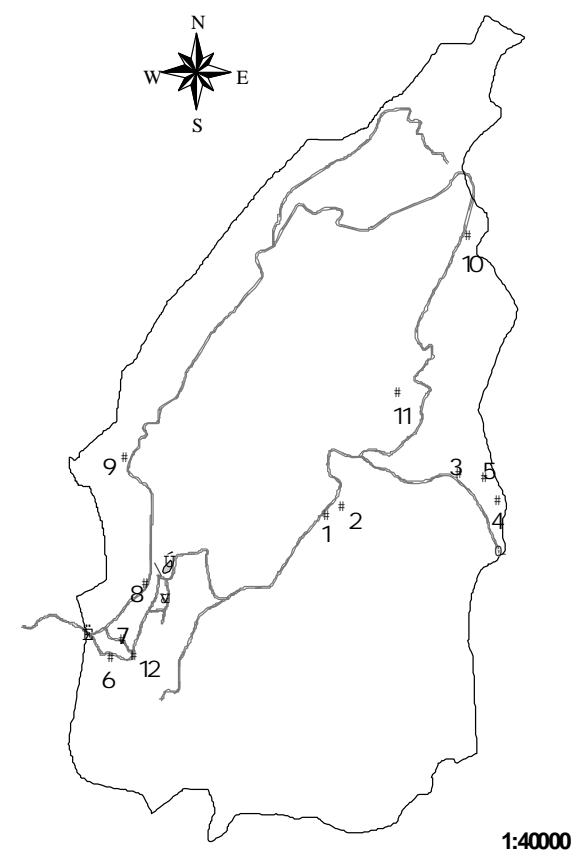

\section{Perfis de solos}

* 1-CAMBISSOLOHÚMCODISTRÓFICOlatossólico

* 2- CAMBISSOLOHÚMCODistrófico léptico

3-NEOSSOLOUTOUCO Distrófico

4- NEOSSOLOLTOUYUCO Distró́fico

5- CAMBISSOLOHÚMCO Distrófico típico

6- CAMBISSOLOHAPUCOTb Distrófico léption

7- CAMBISSOLOHÁPUCOTb Distrófico típico

8- NEOSSOLOUTÓUCODistrófico

9- Horizonte Osobre quartzito

10- ORGANOSSOLOHAPUCO

11 - ESPODOSSOLO, TRROCÁRBICOÓrtico

12 - NEOSSOLO LTÓUCO Húmico típico

Figura 2 - Localização dos perfis de solos coletados no Parque Estadual do Ibitipoca, município de Lima DuarteMG.

Figure 2 - Location of the soil profiles in the I.S.P, Lima Duarte, $M G$. a rocha, por si só, não é um elemento indicador de ambiente.

O quartzito encontrado no parque é, em sua maioria, de granulometria grossa a muito grossa, com freqüentes intercalações de quartzito fino micáceo e, mais raramente, de biotita xisto feldspático (INSTITUTO ESTADUAL..., 1993). Toda a área do PEI é destacada do seu entorno por altitudes maiores, entre 1.000 e $1.780 \mathrm{~m}$, sendo circundada por um relevo mais baixo colinoso, onde predominam gnaisses.

Os solos encontrados na unidade são predominantemente Espodossolos (podzóis). Essa classe é constituída de solos areno-quartzosos com nítida diferenciação e sequiência de horizontes dos tipos A, E, B espódico (Bhs) e C. O horizonte A, de cor escura, contrasta com o horizonte subjacente E álbico, de coloração clara, que, por sua vez, contrasta com o horizonte Bhs abaixo, que possui coloração escura e alaranjada e, em geral, profundidades maiores que $50 \mathrm{~cm}$ (Figura 4).

A vegetação nos Patamares com Espodossolos é de Campo de Altitude, sendo ainda encontrados nas unidades Cristas Ravinadas, Escarpas, Topos Aplainados e Rampas com Vegetação Aberta. São campos encontrados normalmente em altitudes superiores a $1.000 \mathrm{~m}$, com dominância de herbáceas, gramíneas e arbustos esparsos. Estes campos representam a endemicidade que existe no PEI e compreendem, na verdade, um mosaico de tipos vegetacionais que estão aparentemente controlados pela profundidade do solo, associado, assim, à permanência da água no sistema.

As fitofisionomias dos campos encontradas nos Patamares com Espodossolos e das unidades Topos Aplainados e Rampas com Vegetação Aberta são bastante distintas das fitofisionomias dos campos encontradas nas unidades Cristas Ravinadas e Escarpas. Essas diferenças são provavelmente relacionadas com as várias espessuras do solum. Existe uma indefinição na separação destas tipologias. Oliveira-Filho \& Fluminhan-Filho (1999) consideram a vegetação herbácea de altitude associada a afloramento de rocha como sendo campo rupestre e, quando não ocorre afloramento, campo de altitude.

Nas Escarpas e Cristas Ravinadas o solum desenvolvido sobre a rocha é muito pouco profundo, com o espessamento local em zonas de contatos, o que permite pouca retenção de água, levando ao déficit hídrico nos meses mais secos do ano. Nesses campos a tipologia da vegetação é mais herbácea e espaçada. 


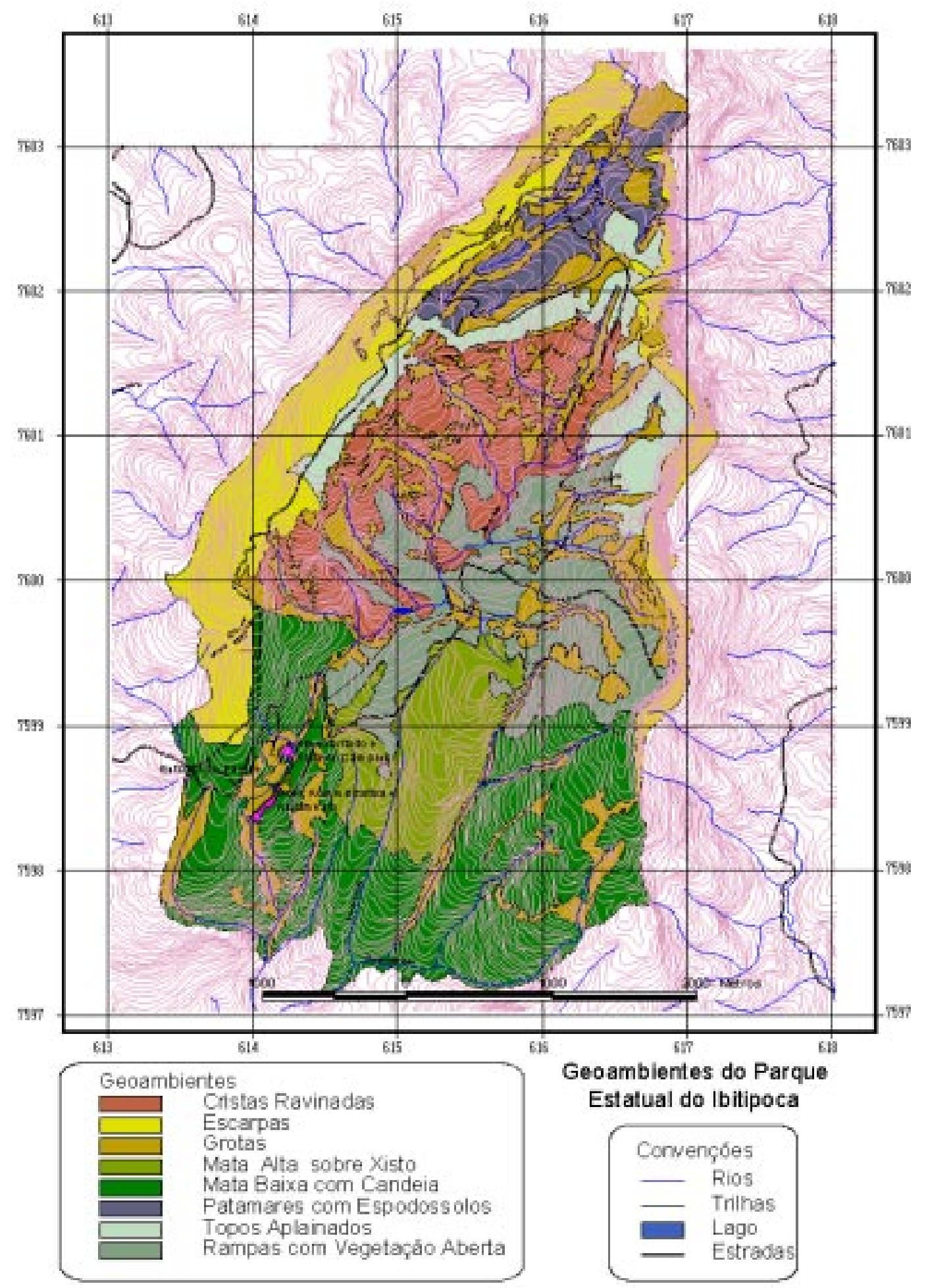

Figura 3 - Mapa de Geoambientes no Parque Estadual do Ibitipoca, município de Lima Duarte-MG. Figure 3 - The geoenvironments in the I.S.P., Lima Duarte, MG. 
Quadro 1 - Geoambientes do Parque Estadual do Ibitipoca e seus atributos Table 1 -Atributtes of the geoenvironments in the I.S.P.

\begin{tabular}{|c|c|c|c|c|c|c|}
\hline Unidade Geoambiental & Rocha & Solo & Relevo & Vegetação & Área $(\%)$ & Perfil \\
\hline $\begin{array}{l}\text { Patamares com } \\
\text { Espodossolos }\end{array}$ & $\begin{array}{l}\text { Quartzito e } \\
\text { sedimentos } \\
\text { arenosos }\end{array}$ & Espodossolos & $\begin{array}{l}\text { Ondulado (altitude } \\
1.760-1.540 \mathrm{~m} \text { ) }\end{array}$ & Campo de Altitude & 4,0 & Tradagens \\
\hline Cristas ravinadas & Quartzito & $\begin{array}{l}\text { Afloramento } \\
\text { de Rocha, } \\
\text { Neossolo Litólico }\end{array}$ & $\begin{array}{l}\text { Escarpado (altitude } \\
1.770-1.390 \mathrm{~m} \text { ) }\end{array}$ & Campo de Altitude & 11,1 & Tradagens \\
\hline Escarpas & Quartzito & $\begin{array}{l}\text { Afloramento } \\
\text { de Rocha, } \\
\text { Neosslolo Litólico }\end{array}$ & $\begin{array}{l}\text { Escarpado a } \\
\text { montanhoso (altitude } \\
1.640-1.370 \mathrm{~m} \text { ) }\end{array}$ & Campo de Altitude & 15,6 & 9 \\
\hline Grotas & Quartzito & $\begin{array}{l}\text { Espodossolo, } \\
\text { Organossolo }\end{array}$ & Inclinado em ravinas & Matas de galeria & 19,2 & $4,11,12$ \\
\hline Mata baixa com cadeia & Quartzito & $\begin{array}{l}\text { Cambissolos álicos } \\
\text { e distróficos }\end{array}$ & $\begin{array}{l}\text { Suave ondulado, } \\
\text { ondulado a forte- } \\
\text { ondulado (altitude } \\
1.680-1.000 \mathrm{~m} \text { ) }\end{array}$ & $\begin{array}{l}\text { Mata aberta com } \\
\text { Candeia }\end{array}$ & 24,4 & $6,10,8,7$ \\
\hline Mata alta sobre xisto & Xisto & $\begin{array}{l}\text { Cambissolos } \\
\text { de caráter } \\
\text { latossólico }\end{array}$ & $\begin{array}{l}\text { Ondulado (altitude } \\
1.500-1.240 \mathrm{~m} \text { ) }\end{array}$ & $\begin{array}{l}\text { Floresta Ombrófila } \\
\text { Densa Montana }\end{array}$ & 7,3 & 1 , Tradagens \\
\hline Topos aplainados & $\begin{array}{l}\text { Quartzito e } \\
\text { sedimentos de } \\
\text { cobertura }\end{array}$ & $\begin{array}{l}\text { Cambissolos } \\
\text { húmicos }\end{array}$ & $\begin{array}{l}\text { Suave ondulado } \\
\text { (altitude } \\
1.780-1.630 \mathrm{~m} \text { ) }\end{array}$ & Campo de Altitude & 6,1 & Tradagens \\
\hline $\begin{array}{l}\text { Rampas com vegetação } \\
\text { aberta }\end{array}$ & $\begin{array}{l}\text { Quartzito, } \\
\text { quartzo-xisto. } \\
\text { Sedimentos } \\
\text { arenosos }\end{array}$ & $\begin{array}{l}\text { Cambissolos } \\
\text { álicos, } \\
\text { Cambissolos } \\
\text { húmicos }\end{array}$ & $\begin{array}{l}\text { Ondulado e suave- } \\
\text { ondulado (altitude } \\
1.700-1.300 \mathrm{~m} \text { ) }\end{array}$ & Campo de Altitude & 12,1 & 2,3 e 5 \\
\hline
\end{tabular}

Em ambientes mais elevados, como no PEI, a umidade atmosférica é maior, devido à precipitação mais elevada $(1.395 \mathrm{~mm})$ e a temperaturas mais baixas, podendo formar neblinas e geadas; em contraste, as características do solo mais raso, relevo acentuado e regime de ventos, favorecem a menor permanência de água no sistema, ocorrendo acentuado déficit hídrico nos meses mais secos do ano. A escassez de água nos microambientes mais elevados condiciona, assim, a existência dessa vegetação.

Nas plantas adaptadas ao estresse hídrico dos campos de altitude, o controle de abertura de estômatos feito pelo ácido abcísico inibe o crescimento das plantas (Taiz \& Zeiger, 1991), condicionando, junto ao oligotrofismo, elementos arbóreos de pequeno porte. Ocorrem ainda adaptações biológicas e morfológicas, convergência de formas, folhas coriáceas, pilosas e com disposição vertical, além de órgãos subterrâneos mais grossos (FUNDAÇÃO...IBGE, 1977; Figueira \& Vasconcelos Neto, 1991).
Nas outras unidades associadas a campos de altitude, onde o solo é mais profundo, bem drenado e com baixa retenção de água, há maior área para exploração radicular da vegetação. Há o estabelecimento de um campo dominado por gramíneas e ciperáceas e por arbustos esparsos.

Nos ambientes sobre quartzito, mas em relevos mais suavizados e solos incipientes (Cambissolos), a profundidade maior parece propiciar uma vegetação um pouco mais densa que os campos rupestres, do tipo savanóide, com inúmeros arbustos anões.

\subsection{Rampas com Vegetação Aberta}

Os solos associados à unidade Rampas com Vegetação Aberta, que ocupam 12,1\% da área total do PEI, estão representados pelos perfis 2, 3 e 5 . Estes solos apresentam profundidade até o horizonte $\mathrm{C}$ de até $45 \mathrm{~cm}$. A colmatação desses vales se deu com material carreado das vizinhanças, com influência local de xistos, como 


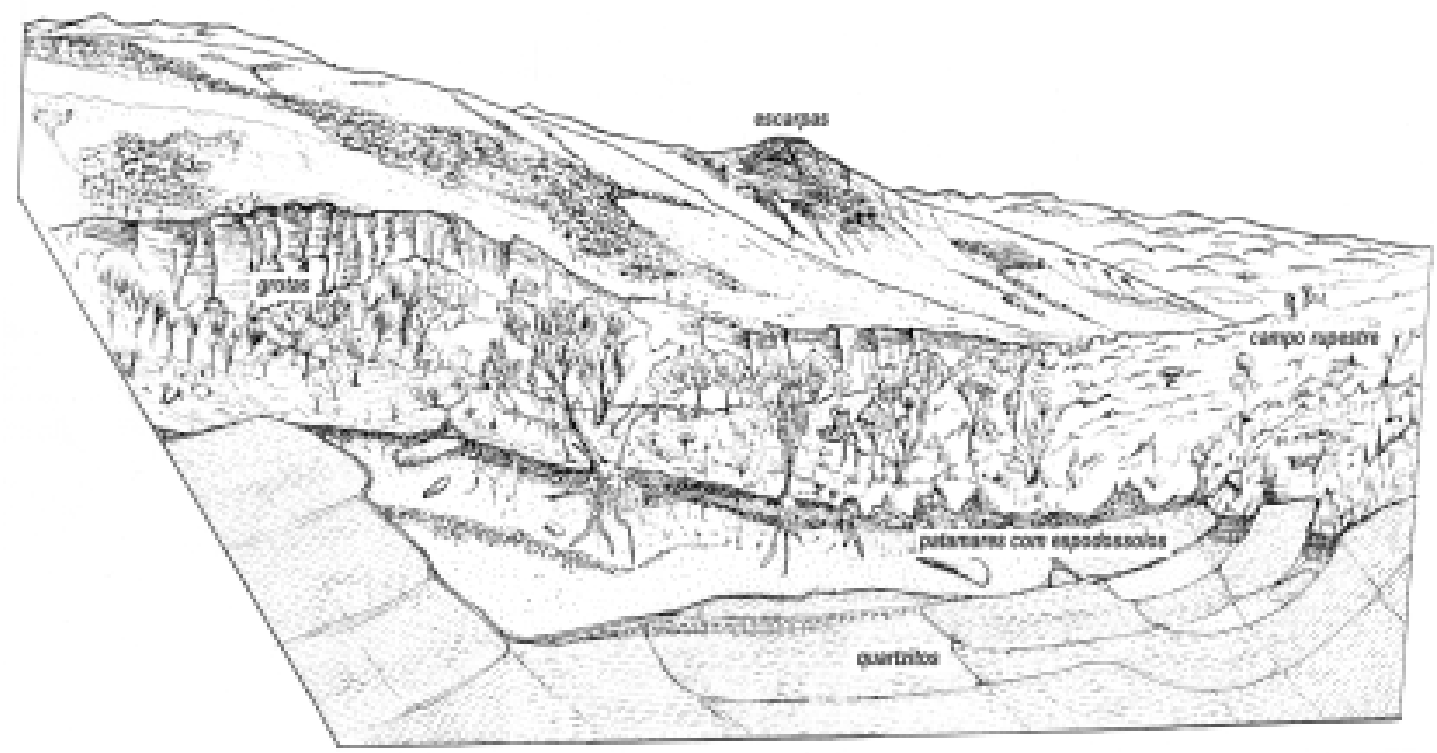

Figura 4 - Bloco-diagrama esquemático e panorâmico do Alto do Ibitipoca, visualizando os patamares com espodossolos com Candeias, grotas, áreas de campo rupestre sobre quartzito e as escarpas que limitam o conjunto serrano com o Mar de Morros, ao fundo.

Figure 4-Schematic and panoramic block-diagram of the Highlands of Ibitipoca, showing the Podzol areas with Candeias, Ravines, Rupiculous field on quartzite and the scarpment that limit the mountain system, with the Mar de Morros in the background.

pode ser observado no perfil 2, que apresenta linha de pedra com fragmentos de xisto rolado. A diversidade de materiais de origem e o acúmulo de substâncias húmicas parecem não afetar a fertilidade e o pH das camadas superficiais destes solos, e todos os solos amostrados caracterizam-se pela fertilidade natural muito baixa e $\mathrm{pHs}$ ácidos (entre 3,1 e 5,1) em todos os horizontes. Assim, a maior profundidade dos solos favorece a presença de uma vegetação graminosa, mais adensada, admitindo pequenos arbustos. O incremento de argila no perfil 2, pela influência do xisto, está também relacionado com o estabelecimento dessa vegetação, com caráter arbóreo mais adensado. No entanto, a melhoria observada nesse ambiente não é suficiente para o estabelecimento de uma vegetação de porte maior, como no ambiente de Mata, possivelmente pela deficiência de água.

\subsection{Cristas Ravinadas}

Nas unidades Cristas Ravinadas $(11,1 \%$ da área total) não há praticamente desenvolvimento de manto pedogenizado, mas principalmente afloramentos rochosos ou Neossolos Litólicos muito rasos. A vegetação que se desenvolve neste substrato raso pode ser classificada como campo rupestre; em alguns locais podem ocorrer campos de altitude.

\subsection{Escarpas}

As Escarpas (15,6\% da área total) apresentam características bastante semelhantes às das Cristas Ravinadas com relação ao solo e à vegetação, quando ocorrem, diferindo-se por apresentar maior declividade, impondo barreiras como uma parede de pedra. O quartzito, neste caso, funciona como uma resistência ao aprofundamento do intemperismo. Os pontos mais elevados das Escarpas oferecem amplo panorama da paisagem, com atrativos visuais, portanto, em locais estrategicamente escolhidos, podem ser explorados como mirantes naturais.

\subsection{Grotas}

São padrões de amplas ravinas encontrados por todo o parque, controlados estruturalmente pelas falhas e diáclases das rochas, onde as águas de percolação abriram lentamente profundas incisões. É por esses ambientes, que correspondem a 19,2\% da área do PEI, que se iniciam as drenagens de cabeceira e formam-se canais de 
drenagem organizados a jusante. Acumulam-se neste local materiais decompostos de regiões mais elevadas e deposições laterais, e solos com maior disponibilidade de água. O sistema ombrófilo favorece o crescimento de uma vegetação de maior porte, formando Matas de Grotas. Esta vegetação propicia proteção à fauna de maior porte e grande diversidade de habitats.

Nas Grotas foram detectados Espodossolos e Organossolos. São solos em geral muito ricos em matéria orgânica, produzida pela vegetação e mantida pelo ambiente oligotrófico, tendo sua decomposição bioquímica retardada devido às condições de encharcamento permanente, à deficiência de oxigênio e às baixas temperaturas e insolação. Embora as Grotas se apresentem muito declivosas, a presença da água nesta unidade é constante, por serem ambientes de acúmulo, com nascentes e cursos d'água intermitentes. A profundidade e a maior umidade dos solos desta unidade propiciam também o desenvolvimento de vegetação mais adensada. As Matas de Grotas predominantes nesta unidade podem atingir grande porte, em busca de maior luminosidade.

As Grotas têm importância especial pelas formações espeleológicas e pelo possível endemismo, como a mata rica em bromélias. Essas cavernas quartzíticas são as principais atrações turísticas do parque, que constitui o principal Distrito Espeleológico Quartzítico de Minas Gerais. Hoje, o Cadastro Nacional de Cavidades Naturais Subterrâneas, da Sociedade Brasileira de Espeleologia, registra a existência de 15 cavernas no parque, com destaque para a Gruta das Bromélias, considerada a maior caverna quartzítica do mundo, restando muitas outras cavernas a serem exploradas no parque.

Nas Grotas, as formações espeleológicas devem merecer atenção especial quanto ao tipo de manejo a receber. A restrição, ou seleção, de acesso em determinadas áreas se faz necessária. A educação ambiental é imprescindível e, neste sentido, o controle do acesso é uma atividade que deve ser implantada em algumas áreas desta unidade. $\mathrm{O}$ pisoteio excessivo por pedestres altera completamente a dinâmica de decomposição e diclagem de matéria orgânica nos solos, o que denota sua fragilidade.

\subsection{Mata Baixa com Candeia}

A vegetação encontrada no geoambiente denominado Mata Baixa com Candeia, com área equivalente a 24,4\% do PEI, é dominada por Candeia (Vanillosmopsis erytropappa Sch. Bip), com ocorrência de outras espécies, sendo esta unidade localmente conhecida como "Mata Baixa”. A presença intensa de líquens na parte aérea desses indivíduos justifica a associação com Floresta de Duendes (Elfin Forest, Floresta Nebular). Embora não tenham sido observadas diferenças aparentes nos níveis de nutrientes no solo, na folha, na casca e nos líquens entre os ambientes em estudo, sem levar em conta a produtividade de biomassa em cada um deles, a vegetação é muito diferenciada. A localização deste geoambiente, contudo, permite constatar que a menor altitude pode estar propiciando o estabelecimento da vegetação local. Os Cambissolos desenvolvidos nessas áreas são arenosos, com, no mínimo, $84 \%$ de areia, o que dificulta o estabelecimento de uma vegetação florestal mais densa, pela excessiva drenagem do solo e rápida lixiviação de bases.

\subsection{Mata Alta sobre Xistos}

A Floresta Ombrófila Densa Altimontana, ocupando uma área correspondente a 7,3\% do PEI, parece estar associada ao aparente aumento nos teores de argila do horizonte B (43\%), bem como aos efeitos das maiores profundidades do solo. $\mathrm{O}$ aumento de argila, em relação aos outros ambientes, é explicado pelo material de origem: xisto - rocha metamórfica intensamente fraturada. Os solos são mais desenvolvidos, e mesmo os Cambissolos Húmicos distróficos latossólicos mostram estrutura mais favorável à manutenção da umidade e maior capacidade de troca de cátions (CTC). Assim, as espécies florestais encontram melhores condições para se estabelecerem, suprindo a deficiência de nutrientes do solo com maior eficiência pela ciclagem. A melhoria nas características físicas dos solos (porosidade, drenagem, textura, umidade, profundidade e permeabilidade) pode compensar propriedades químicas ou biológicas adversas. Conforme observado no campo, a maior produção de biomassa e liter e o horizonte $\mathrm{O}$ mais desenvolvido podem indicar maior produtividade primária e ciclagem mais intensa de nutrientes.

\subsection{Topos Aplainados}

As áreas de cimeira, que interliga as grandes elevações, normalmente ocorrendo entre 1.620 e $1.780 \mathrm{~m}$ de altitude, em relevo suave ondulado, formam superfícies aplainadas pela erosão, sendo, portanto, uma formação em transição, cobrindo uma área entorno de 6,1\% do PEI. Neste geoambiente predominam Cambissolos com caráter latossólico sobre o saprolito residual de xisto, na maioria húmicos, Organossolos e Neossolos litólicos 
sobre o substrato quartzítico. A vegetação é predominantemente campestre, como já descrito anteriormente. É uma área de forte visitação turística, com acesso restrito, em vista do risco de acidentes nas trilhas de difícil conservação e com pouca visibilidade em dias nublados.

\section{CONCLUSÕES}

- A estratificação de geoambientes do Parque Estadual do Ibitipoca identificou oito unidades, com características de fragilidade bem diferenciadas. A vegetação e a profundidade do solo são os melhores indicadores de ambientes, uma vez que os solos são muito pobres quimicamente, de forma generalizada.

- Os 1.488 ha do parque estão divididos entre os geoambientes na seguinte proporção: Patamares com Espodossolos, 4,0\%; Cristas Ravinadas, 11,1\%; Escarpas, 15,6\%; Grotas, 19,2\%; Mata Baixa com Candeia, 24,4\%; Mata Alta sobre Xisto, 7,3\%; Topos Aplainados 6,1\%; e Rampas com Vegetação Aberta, 12,1\%.

- A fitofisionomia e a tipologia da vegetação nos diferentes geoambientes são condicionadas pela disponibilidade de água no solo.

- Os geoambientes de Mata Alta e de Grotas sofrem menor estresse hídrico, em razão das condições físicas do solo (profundidade e textura) e maior retenção de água. Há, nestes dois ambientes, concentrações relativamente maiores de $\mathrm{P}$ e $\mathrm{K}$ do que nos ambientes de campo, e grande fragilidade por causa da visitação.

- Na Mata com Candeia, a pobreza de nutrientes do ambiente parece ser limitante para a não-ocorrência de uma tipologia florestal mais densa. Nos campos de altitude, o bioclima mais frio parece estar relacionado com o estabelecimento desta vegetação. Sua presença difere da vegetação dos campos rupestres, por associar-se a solos mais profundos.

\section{AGRADECIMENTO}

Ao CNPq, pelas bolsas e pelo auxílio; e à Universidade Federal de Viçosa - UFV, ao Instituto Estadual de Florestas - IEF e à Companhia Energética de Minas Gerais CEMIG, pelo apoio.

\section{REFERÊNCIAS BIBLIOGRÁFICAS}

COMPANHIA ENERGÉTICA DE MINAS GERAIS CEMIG. Levantamento aerofotogramétrico. Bias Fortes: 1987. Mapa, escala 1:10.000 (ortofoto).
COSTA, C. M. R. et al. (Orgs.) Biodiversidade em Minas Gerais: um atlas para sua conservação. Belo Horizonte: Fundação Biodiversistas, 1998. 94 p.

EMPRESA BRASILEIRA DE PESQUISA

AGROPECUÁRIA - EMBRAPA. Centro Nacional de Ciências do Solo. Manual de métodos e análises de solo. Rio de Janeiro: 1997. 212 p.

ENVIROMENTAL SYSTEMS RESEARCH INSTITUTE ESRI. Arc/INFO, versão 7.2.1. Redlands: 1994.

ENVIROMENTAL SYSTEMS RESEARCH INSTITUTE ESRI. ArcView GIS, versão 3.1. Redlands: 1998.

FEIO, R.N. Aspectos ecológicos dos anfíbios registrados no parque Estadual do Ibitipoca, Minas Gerais

(Amphibia, Anura). Rio de Janeiro: UFRJ, 1990. 1065 p. Dissertação (Mestrado em Ciências Biológicas/Zoologia) Universidade Federal do Rio de Janeiro, 1990.

FIGUEIRA, J. E. C.; VASCONCELOS NETO, J. Paepalanthus, cupins e aranhas. Ciência Hoje, v. 13, n. 75, p. 20-25, 1991.

FONTES, M. A. L. Análise da composição florística das florestas nebulares do parque Estadual do Ibitipoca, Minas Gerais. Lavras: UFLA, 1997. 50 p. Dissertação (Mestrado em Ciências Florestais) - Universidade Federal de Lavras, 1997.

FUNDAÇÃO INSTITUTO BRASILEIRO DE GEOGRAFIA E ESTATÍSTICA - IBGE. Geografia do Brasil: região suldeste. Rio de Janeiro: SERGRAF, 1977. 667 p.

INSTITUTO DE GEOCIÊNCIAS APLICADAS - IGA. Minas Gerais: Parque Florestal do Ibitipoca. Belo Horizonte: 1986. Mapa, escala 1:10.000.

INSTITUTO ESTADUAL DE FLORESTAS - IEF E TERRA CONSULTORIA E ASSESSORIA EM ESTUDOS GEOAMBIENTAIS. Caracterização geoespeleológica do parque Estadual do Ibitipoca. Belo Horizonte: 1993. 25 p. (Relatório parcial)

OLIVEIRA-FILHO, A. T.; FLUMINHAN-FILHO, M. Ecologia da vegetação do parque Florestal Quedas do Rio Grande. Revista Cerne, v. 5, n. 2, p. 51-64, 1999.

ROCHA, G. C. Solos do parque Estadual do Ibitipoca. In: SEMINÁRIO DE PESQUISA SOBRE O PARQUE ESTADUAL DO IBITIPOCA, 1., 1997, Juiz de Fora.

Anais... Juiz de Fora: Núcleo de Pesquisa em Zoneamento Ambiental da UFJF, 1997. p. 33-42.

SCHAEFER, C. E. R. Ecogeography and human Scenario. Ciência e Cultura, v. 49, n. 4, p. 241-252, 1997.

R. Árvore, Viçosa-MG, v.26, n.6, p.777-786, 2002 
SEMINÁRIO DE PESQUISA SOBRE O PARQUE ESTADUAL DO IBITIPOCA, 1, 1997, Anais.... Juiz de Fora: Núcleo de Pesquisa em Zoneamento Ambiental da UFJF, 1997. $116 \mathrm{p}$.

TAIZ, L.; ZEIGER, E. Plant physiology. California: Benjamin/Cummings Publishing Company, 1991. 559 p.
TRICART, J.; KIEWITDEJONGE, C. Ecogeography and rural management. Harlowl: Longman Scintific, 1992.

WILCOX, A. T. Short term consultant in park and recreation administration to the superior school of Forestry Federal University of Viçosa: Colorado State University. Viçosa: UFV, 1978. p. 40-50. (Relatório) 